\title{
Modification of Boron-doped Diamond Electrodes with Platinum to Increase the Stability and Sensitivity of Haemoglobin-based Acrylamide Sensors
}

\author{
Retno Wulandari, ${ }^{1,2}$ Tribidasari Anggraningrum Ivandini, ${ }^{1}$ \\ Irkham, ${ }^{3}$ Endang Saepudin, ${ }^{1}$ and Yasuaki Einaga ${ }^{3,4^{*}}$ \\ ${ }^{1}$ Department of Chemistry, Faculty of Mathematics and Sciences, Universitas Indonesia, \\ Kampus UI Depok, Depok, Jakarta 16424, Indonesia \\ ${ }^{2}$ Chemical Engineering Department, Faculty of Engineering, Universitas Serang Raya, \\ Jl. Raya Serang-Cilegon KM 5, Banten 42115, Indonesia \\ ${ }^{3}$ Department of Chemistry, Keio University, Hiyoshi 3-14-1, Yokohama 223-8522, Japan \\ ${ }^{4}$ JST ACCEL, Hiyoshi 3-14-1, Yokohama 223-8522, Japan
}

(Received November 6, 2018; accepted December 18, 2018)

Keywords: boron-doped diamond, platinum, surface modification, acrylamide, electrochemical detection

Boron-doped diamond (BDD) electrodes modified with platinum and haemoglobin ( $\mathrm{Hb})$ have been prepared for application as stable and sensitive acrylamide biosensors. The Platinummodified BDD (Pt-BDD) was prepared in several steps, including the wet chemical seeding of Pt particles, the electrochemical overgrowth of Pt seeds, thermal annealing at $700{ }^{\circ} \mathrm{C}$ under $\mathrm{N}_{2}$ atmosphere, as well as refresh and activation steps of Pt-BDD by cyclic voltammetry (CV). The characterization of the prepared Pt-BDD using scanning electron microscopy with energydispersive spectroscopy (SEM-EDS) and X-ray photoelectron spectroscopy (XPS) showed that the method can deposit Pt homogenously on the BDD surface with an average particle size of around $200 \mathrm{~nm}$. The Raman results showed that the treatment steps during modification did not damage the $\mathrm{sp}^{3}$ carbon in the BDD structure. After modification with $\mathrm{Hb}$, the modified BDD was examined for acrylamide detection. CVs of Hb-Pt-modified BDD (Hb-Pt-BDD) in $0.2 \mathrm{M}$ acetate buffer saline (ABS) $(\mathrm{pH} 4.8)$ containing acrylamide in the concentration range of 0.01 to $1 \mathrm{nM}$ showed linear responses with a detection limit of $0.0085 \mathrm{nM}$ and a quantification limit of 0.026 $\mathrm{nM}$. The excellent stability of the prepared Pt-BDD was confirmed as it showed the reusability of Pt-BDD by removing the $\mathrm{Hb}$ adduct without removing $\mathrm{Pt}$ on the BDD surface.

\section{Introduction}

Acrylamide is a neurotoxin and a potential carcinogenic substance,${ }^{(1-3)}$ formed by the reaction between reducing sugars, such as glucose and asparagine. The Maillard reaction mechanism is considered to be responsible for acrylamide formation during food processing, especially in high-starch foods during cooking at high temperatures $\left(>120^{\circ} \mathrm{C}\right) .{ }^{(2)}$ The detection of acrylamide has become necessary to ensure food safety. The standard detection methods of

*Corresponding author: e-mail: einaga@chem.keio.ac.jp

https://doi.org/10.18494/SAM.2019.2192 
acrylamide, including liquid chromatography mass spectrometry/mass spectrometry and gas chromatography mass spectrometry (LCMS/MS and GCMS), offer high sensitivity, selectivity, stability, and repeatability. ${ }^{(4)}$ However, these methods require high testing cost and skilled laboratory technicians, which cannot meet the criteria for a real-time and on-line detection of acrylamide in foods. Therefore, it is highly important to develop a simple, sensitive, and lowcost method for acrylamide detection in food samples.

On the other hand, the development of biosensors for acrylamide determination is attracting much attention owing to their ability to do real-time measurement and relatively low cost. One of the popular methods in the development of acrylamide biosensors was reported to employ the redox signal of haemoglobin $(\mathrm{Hb}) .{ }^{(5-7)} \mathrm{Hb}$ is a redox protein consisting of four polypeptide chains. Each of them contains one heme group. ${ }^{(8)}$ Iron in the heme groups carries the electroactive property of $\mathrm{Hb}$ that changes in the presence of acrylamide, resulting in the signal responses of acrylamide.

$\mathrm{Hb}$-based biosensors for acrylamide were developed using gold nanoparticle-modified ITO glass, single-wall carbon nanotubes, and boron-doped diamond (BDD) electrodes. ${ }^{(1,6-8)}$ BDD was selected owing to its superior properties, such as wide potential window and small background current, which are required in the development of sensors. ${ }^{(7,9)}$ However, the problem with low stability and sensitivity was often observed because of the instability of electromediators, i.e., metal particles on the surface BDD. ${ }^{(10,11)}$ Electromediators in acrylamide biosensors play an important role in electron transfer between $\mathrm{Hb}$ and electrodes, while the unfavourable orientation of $\mathrm{Hb}$ molecules on the electrode surface and the distance between the heme centre and the electrode surface are the main reasons for the slow kinetics of the electron transfer. ${ }^{(12,13)}$

Some techniques that are generally used to modify BDD with metals have been reported, such as electrochemical deposition, photochemical reaction, and ion implantation. ${ }^{(10,11,14-16)}$ However, these methods could not achieve a suitable amount or high stability of the deposited metal on the surface BDD. ${ }^{(10,11,14)}$ Moreover, the ion implantation method gives a more promising result that indicates the high stability of metal particles, but it needs a quite expensive special instrument. ${ }^{(10,11)}$

In this study, we propose to develop platinum-modified BDD (Pt-BDD) with high stability and sensitivity for application in acrylamide biosensors. The electrochemical reduction technique is employed to deposit platinum particles. However, to prepare a stable Pt-BDD, thermal annealing was applied to BDD after modification with platinum. For acrylamide detection, a Hb-platinum-modified BDD (Hb-Pt-BDD) surface was used. The high stability of Pt particles on the BDD surface, as well as that of $\mathrm{Hb}$ molecules coated on Pt-BDD, generates an increase in electron transfer from the electrolyte to the electrode, and accordingly, provides a higher sensitivity for the determination of acrylamide.

\section{Materials and Methods}

\subsection{Materials and instruments}

The BDD films laboratory-made in Keio University, Japan were prepared by microwave plasma-assisted chemical vapour deposition (MPCVD, CORNES Technologies/ASTeX-5400) 
using a $0.1 \%$ boron-to-carbon ratio for the precursor solution. ${ }^{(17,18)}$ A (100) silicon wafer was used as the support. The BDD film thickness of around $1 \mu \mathrm{m}$ was observed. $\mathrm{H}_{2} \mathrm{PtCl}_{6} \cdot 6 \mathrm{H}_{2} \mathrm{O}$, $\mathrm{NaBH}_{4}$, and $\mathrm{NaOH}$ were supplied by Wako Inc. (Japan), while human Hb H7379 and acrylamide were purchased from Sigma-Aldrich. All chemicals were used as received without further purification.

\subsection{Modification of platinum at BDD electrode}

The modification of platinum at the BDD electrode (or Pt-BBD) was performed by following the procedures of Gao et al. with some modifications. ${ }^{(19)}$ Briefly, Pt seeds were grown on the BDD surface by dropping $10 \mu \mathrm{L}$ of $1.0 \mathrm{M} \mathrm{NaBH}_{4}$ dissolved in $0.1 \mathrm{M} \mathrm{NaOH}$. Then, $40 \mu \mathrm{L}$ of $1.0 \mathrm{mM} \mathrm{H}_{2} \mathrm{PtCl}_{6}$ solution was added dropwise. After washing and drying, the electrochemical overgrowth of Pt seeds was conducted in $5 \mathrm{~mL}$ of $1.0 \mathrm{mM} \mathrm{H}_{2} \mathrm{PtCl}_{6}$ solution at a constant potential of $-0.2 \mathrm{~V}$ supplied gradually in 1 to $2,3,4$, and $5 \mathrm{~min}$ (total $15 \mathrm{~min}$ ). After this step, the Pt-BDD electrode was subjected to rapid thermal annealing at $700{ }^{\circ} \mathrm{C}$ for $5 \mathrm{~min}$ in $\mathrm{N}_{2}$ atmosphere, followed by a refresh step with cyclic voltammetry (CV) between -0.5 and $+1.5 \mathrm{~V}$ at a scan rate of $200 \mathrm{mV} / \mathrm{s}$ for 100 cycles in $0.1 \mathrm{M} \mathrm{H}_{2} \mathrm{SO}_{4}$. In the last step, further activation steps were performed using a deposition potential of $-0.2 \mathrm{~V}$ gradually within $15 \mathrm{~min}$ to refresh the Pt surface. Figure 1 shows the schematic of the modification process of Pt-BDD.

\subsection{Modification of Pt-BDD electrodes with $\mathbf{H b}$}

The modification of Pt-BDD with $\mathrm{Hb}$ was performed by dropping $15 \mu \mathrm{L}$ of $0.2 \mathrm{M}$ acetate buffer saline (ABS) solution ( $\mathrm{pH}$ 4.8) containing $0.15 \mathrm{mM} \mathrm{Hb}$ on Pt, BDD, and Pt-BDD electrodes (1 $\times 1 \mathrm{~cm}^{2}$ ) and left for $24 \mathrm{~h}$. The obtained Hb-Pt BDD electrodes were then rinsed with Milli-Q water and dried in a stream of nitrogen gas. The electrodes were stored in ABS solution at $4{ }^{\circ} \mathrm{C}$ when not in use.

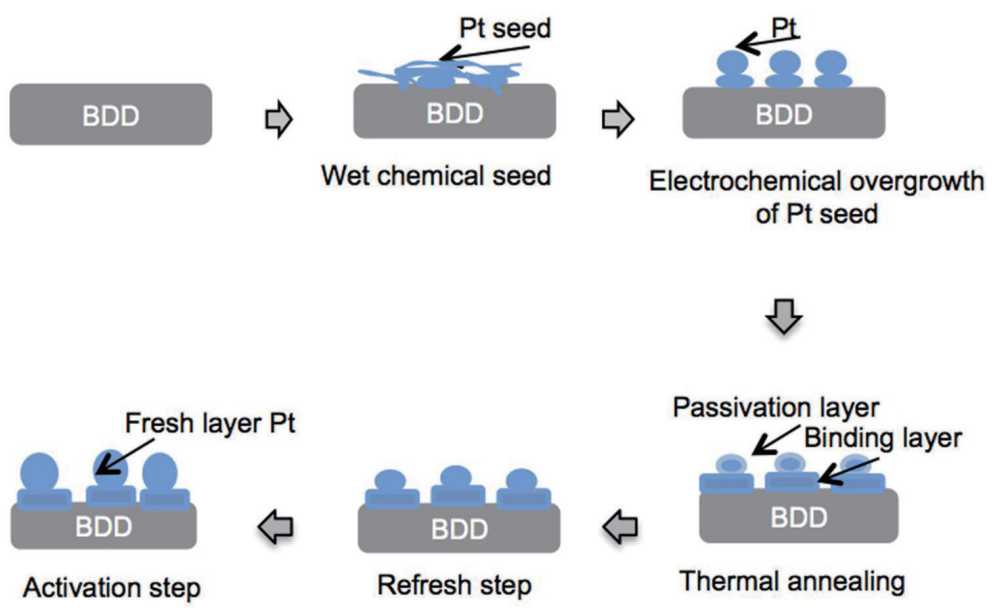

Fig. 1. (Color online) Schematic representation of the Pt modification at BDD. 


\subsection{Electrode characterization}

The modified BDD was characterized by scanning electron microscopy with energydispersive X-ray spectroscopy (SEM-EDX, JEOL JCM-6000), X-ray photoelectron spectroscopy (XPS, JEOL JPS-9010TR), and X-ray diffraction (XRD, Bruker D8 Discover), and Raman spectra were recorded with an Acton SP2500 (Princeton Instruments) with excitation at $532 \mathrm{~nm}$ from a green laser diode at ambient temperature.

\subsection{Electrochemical measurements}

Electrochemical measurements were conducted using a potentiostat (PGSTAT302N, AUTOLAB Instrument). A three-electrode system was used with $\mathrm{Ag} / \mathrm{AgCl}$ reference and $\mathrm{Pt}$ counter electrodes. The working electrode was either BDD, Pt-BDD, Hb-Pt-BDD, Hb-Pt, or $\mathrm{Hb}$-BDD. The use of hemoglobin was carried out in the same way as the modification of the PtBDD electrode with hemoglobin as described in Sect. 2.3. CV was used for the electrochemical measurements of acrylamide standard solutions and samples on $\mathrm{Hb}-\mathrm{Pt}$ BDD electrodes from the potentials of -0.5 to $1.5 \mathrm{~V}$ at a scan rate of $100 \mathrm{mV} / \mathrm{s}$. The electrode area for CV was $0.28 \mathrm{~cm}^{2}$. The standard solutions were prepared in $0.2 \mathrm{M}$ ABS solution $(\mathrm{pH} 4.8)$ with various acrylamide concentrations $(0.01-0.1 \mathrm{nM}){ }^{(20)}$

\section{Results and Discussion}

\subsection{Modification of BDD with Pt particles}

Pt particles were seeded on the BDD surface by the chemical reduction reaction of $\left[\mathrm{PtCl}_{6}\right]^{2-}$ in $\mathrm{NaBH}_{4}$ solution. $\mathrm{NaBH}_{4}$ was selected in the growth of Pt seeds owing to not only its strong reduction behaviour but also the nature of the BDD surface with $\mathrm{H}$ termination, which has a relatively positive charge of the $\mathrm{C}-\mathrm{H}$ surface. ${ }^{(21,22)}$ Accordingly, $\mathrm{BH}_{4}{ }^{-}$anions were expected to adsorb on the BDD surface and simultaneously induce the chemical reduction of $\left[\mathrm{PtCl}_{6}\right]^{2-}$ to $\mathrm{Pt}$ particles on the BDD surface.

Figures 2(a) and 2(b) show the SEM characterization of the original BDD surface in comparison with the Pt-BDD surface in wet chemical seeding steps. The platinum particles tend to assemble at one point owing to the strong reducing agent $\left(\mathrm{NaBH}_{4}\right)$, which rapidly reacts with the $\left[\mathrm{PtCl}_{6}\right]^{2-}$ ion solution and is difficult to control. This process involves the binding or seeding of a Pt metal precursor onto the electrode surface by physical adsorption. When the chemical reduction changes the Pt metal precursor to Pt metals, it will separate from the solution. On the other hand, $\mathrm{BH}_{4}{ }^{-}$of $\mathrm{NaBH}_{4}$ absorbed on the electrode surface cannot widely diffuse (spread) owing to the nonuniform electronic properties of BDD electrodes. ${ }^{(21,22)}$

To overcome this problem, the electrochemical overgrowth of seeds was performed. A potential of $-0.2 \mathrm{~V}$ was applied with an incremental time increase from 1 to $2,3,4$, and $5 \mathrm{~min}$ (total of $15 \mathrm{~min}$ ). This step was intended to distribute the Pt nanoparticles homogeneously on the BDD surface. ${ }^{(23)}$ In addition, the electrochemical overgrowth of $\mathrm{Pt}$ seeds enlarged the $\mathrm{Pt}$ 


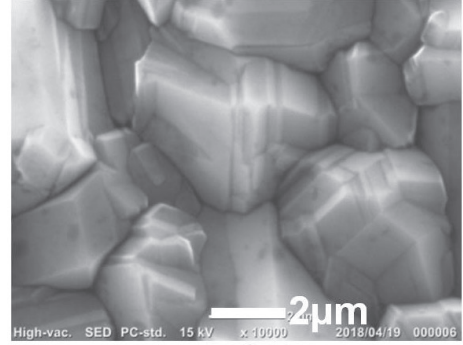

(a)

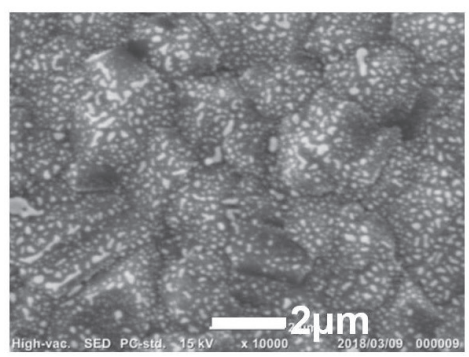

(d)

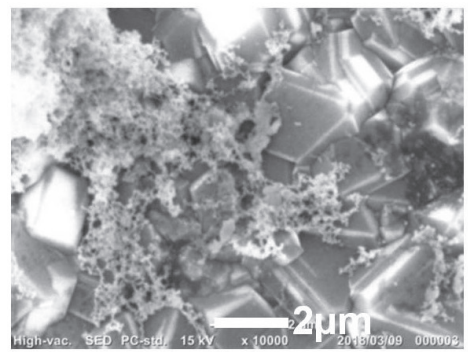

(b)

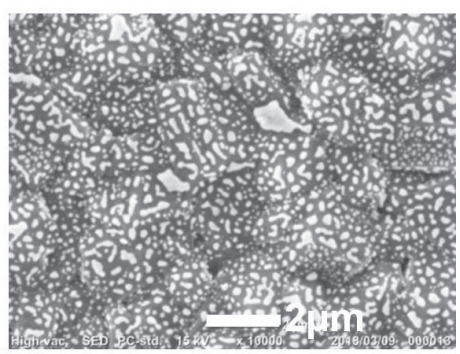

(e)

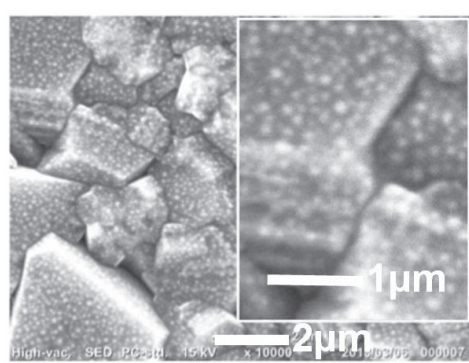

(c)

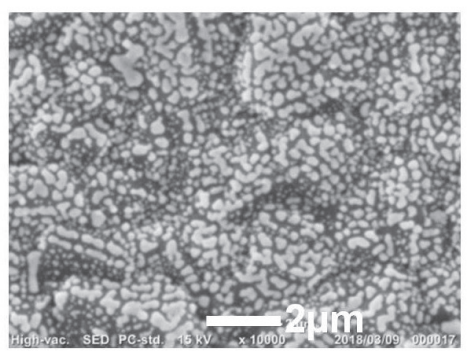

(f)

Fig. 2. SEM images of (a) original BDD and Pt-BDD surfaces after (b) wet chemical seeding, (c) electrochemical overgrowth of Pt seeds, (d) thermal annealing, (e) refresh step, and (f) activation step. Inset of Fig. 2(c) shows the magnification of the figure.

nanoparticles instead of agglomerating them at the BDD substrates. Figure 2(c) shows that the Pt nanoparticles dispersed on the BDD electrode in a wide surface area, compared with the seeding result in Fig. 2(b). Moreover, the electrochemical overgrowth of seeds reduced the rate of agglomeration in wet chemical seeding steps.

However, combining wet chemical seeding and the electrochemical overgrowth of seeds to modify BDD with platinum resulted in unstable Pt particles, which were easily removed by heavy flow or washing in an ultrasonic tube. Because of this stability problem, annealing at a temperature of $700{ }^{\circ} \mathrm{C}$ for $5 \mathrm{~min}$ in $\mathrm{N}_{2}$ atmosphere was conducted.

Annealing was conducted to increase the surface energy of BDD, in order to form an epitaxial lattice structure between the BDD surface and Pt. ${ }^{(15)}$ Figure 2(d) shows the quality improvement of $\mathrm{Pt}$ growth on the BDD surface. During annealing, $\mathrm{N}_{2}$ gas is drained to inhibit the formation of oxidized platinum at Pt-BDD. BDD with low surface energy is more stable because of the lower number of dangling bonds, making it more difficult for Pt to attach. The more dangling bonds, the easier it will be for Pt to attach to the BDD surface. At the beginning, the growth of the epitaxial lattice layer formed Pt islands owing to the lattice incompatibility between Pt and BDD. In general, the lattice tension, surface energy, and interface of the system play a direct important role in the epitaxial lattice layer by layer or island formation. ${ }^{(16)}$

$\mathrm{CV}$ was performed to study the processes occurring at every step during the deposition of Pt on the BDD surface. Before modifying with Pt [Fig. 3(a)], no peak was observed in the voltammogram of $0.1 \mathrm{M} \mathrm{H}_{2} \mathrm{SO}_{4}$ on the original $\mathrm{BDD}$ surface in the potential range of -1.5 to $+1.5 \mathrm{~V}$, indicating that the BDD surface was clean. ${ }^{(9)}$ The voltammograms obtained after Pt 


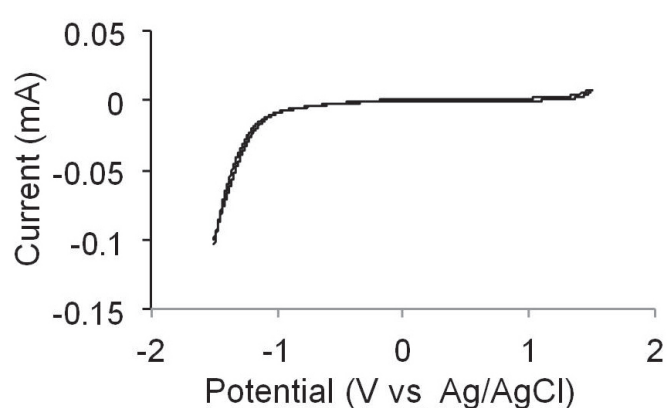

(a)

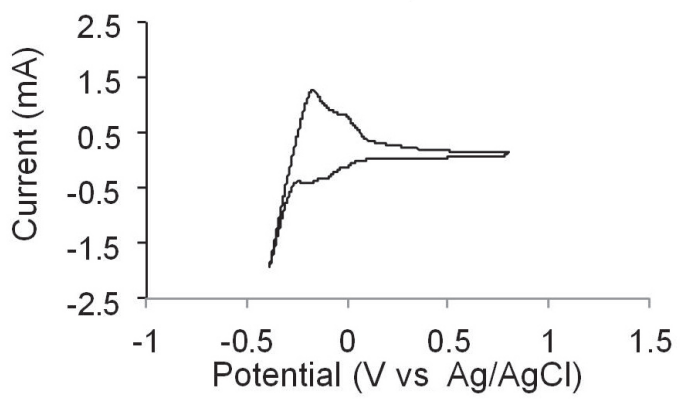

(c)

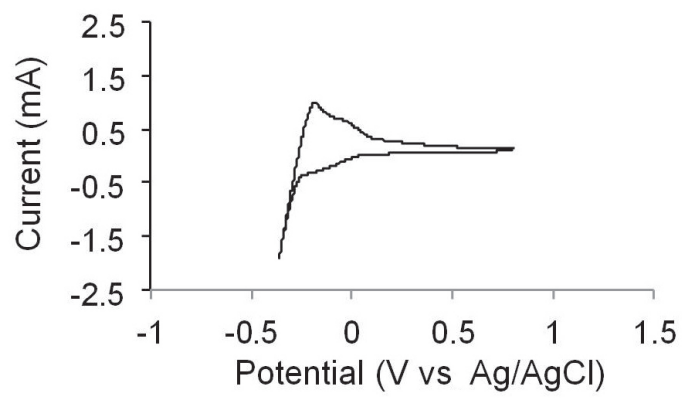

(e)

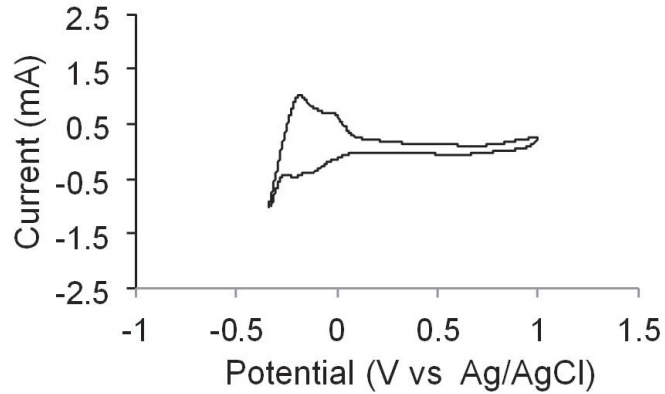

(b)

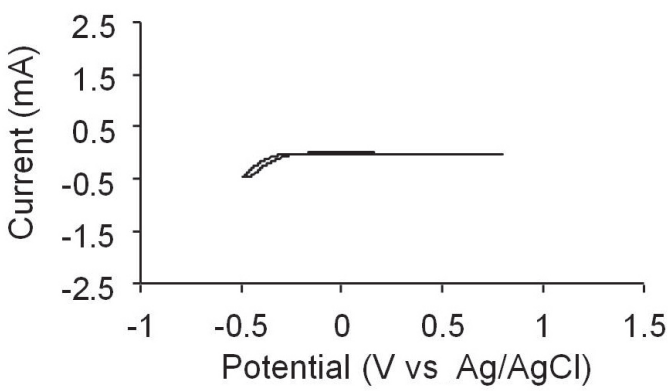

(d)

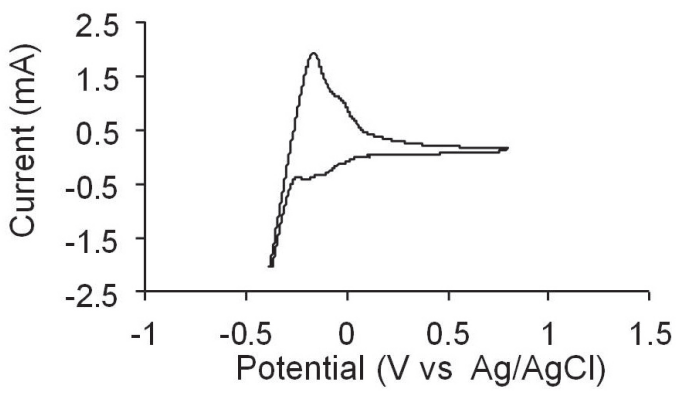

(f)

Fig. 3. Cyclic voltammograms of $0.1 \mathrm{M} \mathrm{H}_{2} \mathrm{SO}_{4}$ at (a) original BDD and Pt-BDD surfaces after (b) wet chemical seeding, (c) electrochemical overgrowth of Pt seeds, (d) thermal annealing, (e) refresh step, and (f) activation step.

seeding and electrochemical overgrowth of Pt seeds [Figs. 3(b) and 3(c)] exhibit two peaks related to two adsorption/desorption reactions of hydrogen. These peaks indicate the presence of active Pt particles on the BDD surface. ${ }^{(23)}$ The voltammogram obtained after thermal annealing [Fig. 3(d)] shows no peaks and only the peak background of BDD remains. These results indicate loss of reactivity at the Pt particle to hydrogen adsorption/desorption. This might happen owing to the carbon compound that dissolved in platinum and settled on the metal surface during cooling, ${ }^{(24,25)}$ which led to the deactivation of the Pt-BDD surface by the formed passivation layer after the annealing treatment.

To refresh the Pt-BDD surface electrode, $\mathrm{CV}$ was repeated 100 times in $0.1 \mathrm{M} \mathrm{H}_{2} \mathrm{SO}_{4}$ solution to dissolve the impurities on the Pt nanoparticle surface on the BDD electrode (refresh step). The SEM image [Fig. 2(e)] shows an increase in Pt particle size at BDD after the refresh step. This confirmed the voltammogram in Fig. 3(e), which shows peaks of platinum. However, 
the peak current is still lower than that of BDD after the electrochemical overgrowth of Pt seeds [Fig. 3(c)], suggesting that the removal of the passive layers is incomplete as indicated by the decrease in the active electrochemical area of Pt.

The activation step was performed on the Pt-BDD surface in order to obtain new active Pt nanoparticles with a large area. This step was carried out by an electrodeposition method similar to the gradual electrochemical growth at the $-0.2 \mathrm{~V}$ potential in $15 \mathrm{~min}$. After the activation step, the size and distribution of Pt particles on the BDD surface increased as shown in Fig. 2(f). Observation by EDX confirmed that Pt particles on the BDD surface were around 98.4 in mass percentage. Further confirmation of the voltammetry results in the activation step showed that the peak current clearly increased after reactivation with electrodeposition [Fig. $3(\mathrm{f})]$.

To confirm the effects of all the treatments on the structure of BDD ( $\mathrm{sp}^{3}$ carbon), Raman characterization was performed (Fig. 4). All spectra show a sharp sp 3 peak at around $1330 \mathrm{~cm}^{-1}$ and the absence of the $\mathrm{sp}^{2}$ peaks at around $1500 \mathrm{~cm}^{-1}$, indicating that all the steps in the above treatments did not damage the $\mathrm{sp}^{3}$ structure of BDD. ${ }^{(17,18,26)}$

The chemical composition of the BDD surface before and after modification was studied by XPS (Fig. 5). All spectra show peaks of $\mathrm{Pt}_{4 \mathrm{f}_{7 / 2}}$ and $4 \mathrm{f}_{5 / 2}$ at binding energies of around 71.0 and $74.6 \mathrm{eV}$, respectively, confirming that Pt was successfully deposited on BDD. The Pt peak intensity after wet chemical seeding (line a) was very low as the interaction between Pt and the BDD surface relied on the adsorption of $\mathrm{BH}_{4}{ }^{-}$with metal ions. The intensities of both $\mathrm{Pt}$ peaks increased after the electrochemical overgrowth of Pt seeds, which later decreased after the thermal annealing step in $\mathrm{N}_{2}$ atmosphere, confirming the formation of the passivation layer during this step. After the refresh step, the Pt peak intensity did not significantly increase, suggesting that the step could not remove the passive layer completely. However, the peak increased after the activation step, suggesting the increase in the amount of active platinum on the surface of the electrode.

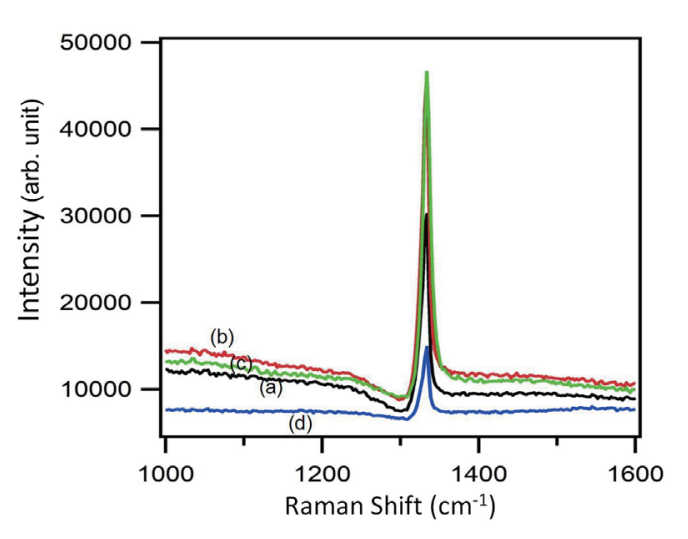

Fig. 4. (Color online) Raman spectra of the original bare BDD (line a) and Pt-BDD after wet chemical seeding (line b), thermal annealing (line c), and activation step (line d).

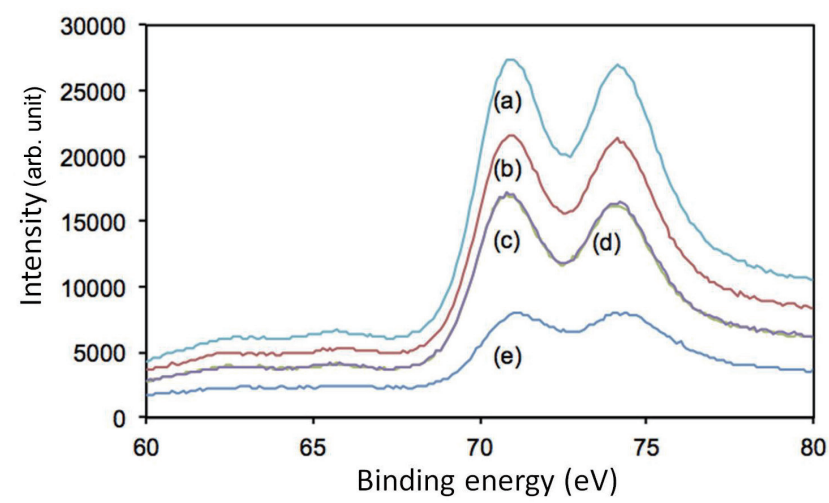

Fig. 5. (Color online) XPS spectra of Pt-BDD after wet chemical seeding (line a), electrochemical overgrowth of Pt seeds (line b), thermal annealing (line c), refresh step (line d), and activation step (line e). 
XRD patterns were measured to study the crystal structure of the Pt-BDD surface during the modification steps (Fig. 6). A sharp peak at $2 \theta$ of $43.23^{\circ}$ indicated the presence of the (111)-diamond phase of the BDD film. ${ }^{(21,27)}$ The Pt deposited on the BDD surface formed a face-centered cubic (fcc) pattern with sharp peaks of Pt (111) and Pt (220) at $2 \theta$ values of 39.73 and 75.22, respectively. The sharp peaks observed also indicated that the Pt particles deposited by this method produced crystalline Pt.

After the wet chemical seeding steps (Fig. 6, line a), the XRD spectrum showed that the Pt (111) and Pt (220) peaks slightly shifted to 40.08 and 75.43, respectively. Moreover, the decrease in peak intensity confirmed the formation of the passivation layer at Pt particles during annealing (Fig. 6, line b). However, the peaks of Pt (111) and Pt (220) shifted back to $2 \theta$ values of around 39.79 and 75.13 after the activation step (Fig. 6, line c), although they could not recover to the initial $2 \theta$ resulting in the seeding step. This is probably caused by the deposition of Pt occurring only on the Pt particles, which has been successfully activated on the BDD surface. As the activation step could not totally remove the passivation surface, the area that could be electrodeposited with Pt became smaller than that obtained by the wet chemical seeding step.

\subsection{Response measurements of acrylamide biosensor}

$\mathrm{Hb}$ was immobilized by dropping the $\mathrm{Hb}$ solution on the Pt-BDD surface. Hb contains electroactive heme groups inside its globin structure. In metal-based electrodes, such as gold and platinum, the measurements of $\mathrm{Hb}$ by $\mathrm{CV}$ resulted in an oxidation peak of the quasireversible reaction of $\mathrm{Hb}-\mathrm{Fe}^{3+} / \mathrm{Hb}-\mathrm{Fe}^{2+}$ as an active center. ${ }^{(6,7)}$ However, in the presence of acrylamide, adduct compounds of $\mathrm{Hb}$ are formed as reaction products between acrylamide and $-\mathrm{NH}_{2}$ of valine terminals. ${ }^{(5,28)}$ Such adduct compounds can change the Hb structure, affecting the accessibility of the active center of $\mathrm{Hb}$ to electrodes. Thus, slower kinetics occurred and the oxidation current peak intensity of the active center of heme decreased. ${ }^{(1,29,30)}$

Figure 7 shows a comparison of $\mathrm{CV}$ at various concentrations of acrylamide in $0.1 \mathrm{M}$ ABS $(\mathrm{pH}$ 4.8) at $\mathrm{Hb}-\mathrm{Pt}, \mathrm{Hb}-\mathrm{BDD}$, and Pt-BDD electrodes. Although the decrease in peak current was observed at around $+1.0 \mathrm{~V}(\mathrm{vs} \mathrm{Ag} / \mathrm{AgCl})$ at the $\mathrm{Hb}-\mathrm{Pt}$ electrode [Figs. 7(a) and 7(b)], the

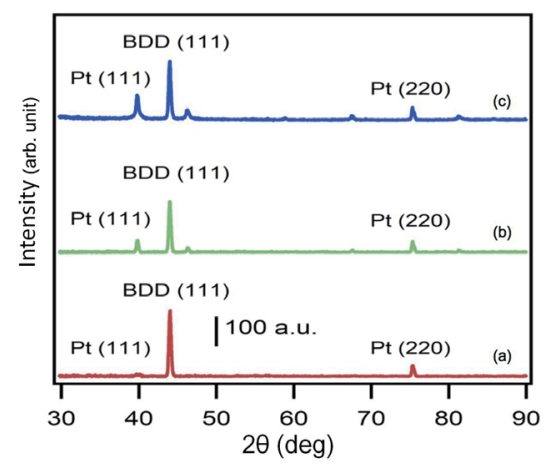

Fig. 6. (Color online) XRD patterns of Pt-BDD after wet chemical seeding (line a), thermal annealing (line b), and activation step (line c). 


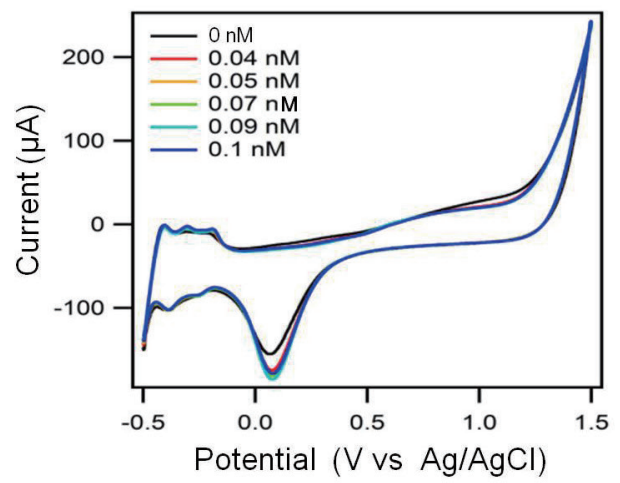

(a)

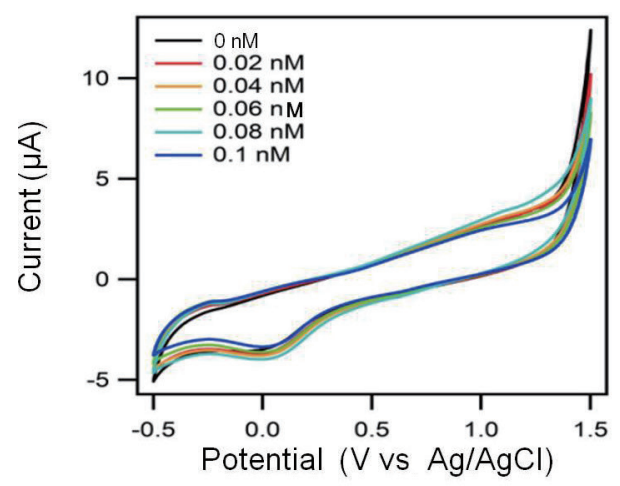

(c)

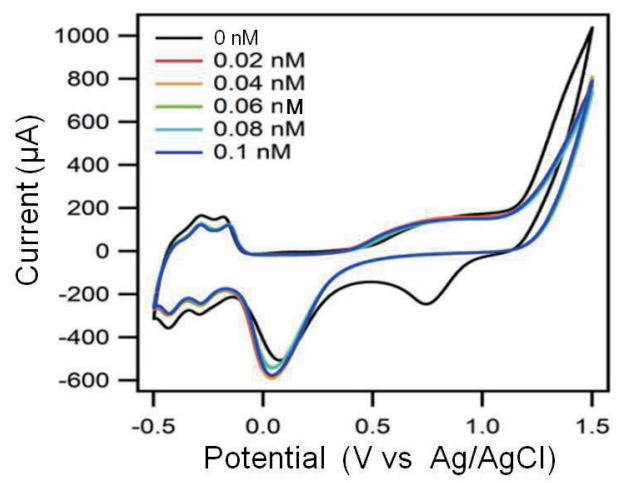

(e)

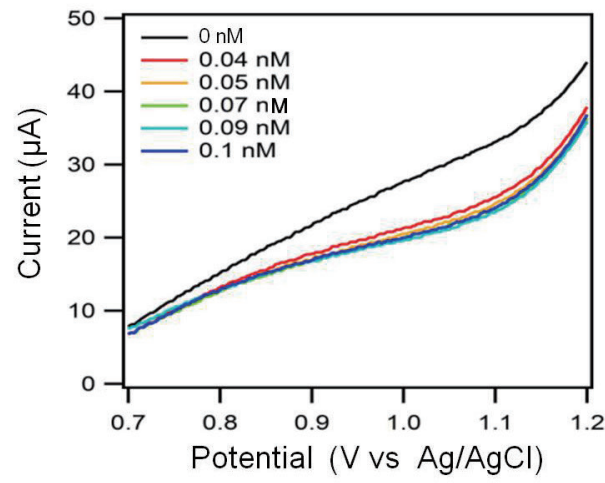

(b)

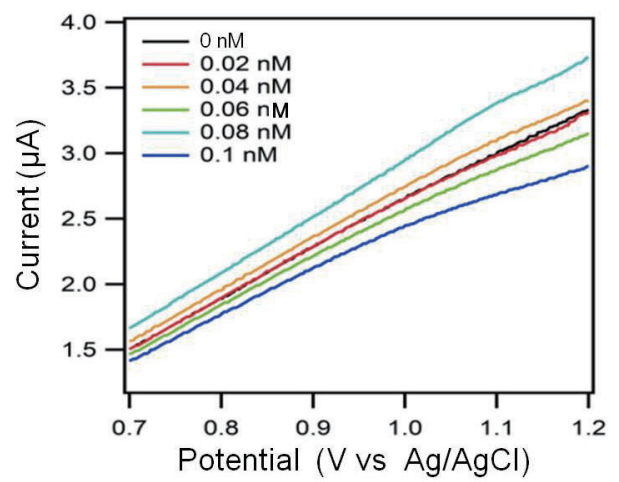

(d)

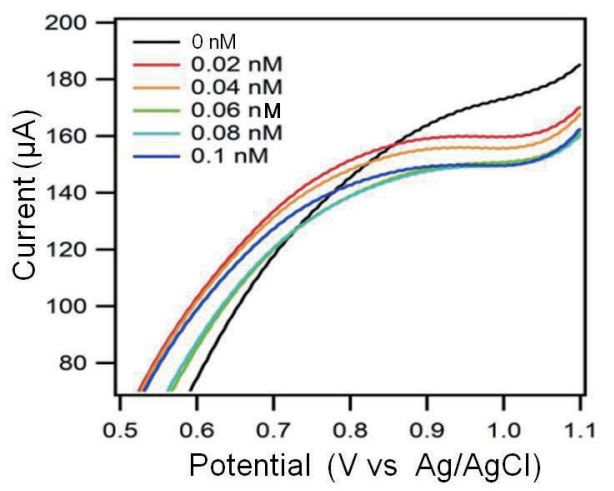

(f)

Fig. 7. (Color online) Cyclic voltammograms of various concentrations of acrylamide and its related magnification at (a and b) Hb-Pt, (c and d) Hb-BDD, and (e and f) Pt-BDD electrodes.

difference was too small to observe. On the other hand, there was no correlation observed between the peak currents with the increase in acrylamide concentration at the Hb-BDD electrode since BDD has very weak responses to $\mathrm{Hb}$ [Figs. 7(c) and 7(d)]. In the case of the Pt-BDD electrode [Figs. 7(e) and 7(f)], although the oxidation reduction of Pt was observed, acrylamide is not particularly electroactive at both the Pt and BDD electrodes, resulting in the lack of correlation between current and acrylamide concentration. 
In $\mathrm{Hb}$-Pt-BDD (Fig. 8), typical oxidation peaks at around $+1.0 \mathrm{~V}$ (vs $\mathrm{Ag} / \mathrm{AgCl}$ ) were observed to decrease with the increase in acrylamide concentration. The plots of the maximum peak currents of acrylamide in the concentration range of 0.01 to $0.1 \mathrm{nM}$ show good linearity with $R^{2}=0.991$. The estimated limit of detection (LoD) calculated from the intercept of the linear equation added by standard deviation times three was found to be $0.0085 \mathrm{nM}$, while that of quantification (LoQ) was $0.026 \mathrm{nM}$. This LoQ was the lowest concentration that could be measured in real measurements. The results indicated that Hb-Pt-BDD could be a promising electrode for application in an acrylamide biosensor.

Lastly, the stability of Pt-BDD was examined. Figure 9 shows the SEM images of $\mathrm{Hb}-$ Pt-BDD after preparation, application as acrylamide sensors, and cleaning $\mathrm{Hb}$. There was no significant difference between the results obtained before and after application as the acrylamide sensors as also observed in the voltammetry responses of acrylamide. The Hb-PtBDD electrode could be applied with good stability for at least 10 times to make calibration curves of acrylamide in the concentration range of 0.01 to $0.1 \mathrm{nM}$ before the responses decreased.

EDX measurements were used to characterize the changes observed in the electrodes before and after application as acrylamide sensors. Table 1 shows that the chemical composition of the electrodes changed before and after applications. Although the mass percentage of Fe on the electrode surface decreased, the Pt composition increased significantly from 81.27 to $97.98 \%$, suggesting that some amount of $\mathrm{Hb}$ was released to expose platinum particles under the $\mathrm{Hb}$ film.

To remove $\mathrm{Hb}$ from the $\mathrm{Pt}-\mathrm{BDD}$ surface, cleaning with $\mathrm{CV}$ in the potential range of -1.0 to $+2.0 \mathrm{~V}$ (vs $\mathrm{Ag} / \mathrm{AgCl}$ ) in $0.1 \mathrm{M} \mathrm{NaClO}_{4}$ was performed. The SEM image of Pt-BDD after cleaning with CV [Fig. 9(c)] shows that the figure was comparable to that of BDD before modification with $\mathrm{Hb}$ [Fig. 2(e)]. However, further study by EDX shows that the mass percentage of Pt increased after cleaning (Table 1). In contrast, the mass percentage of Fe

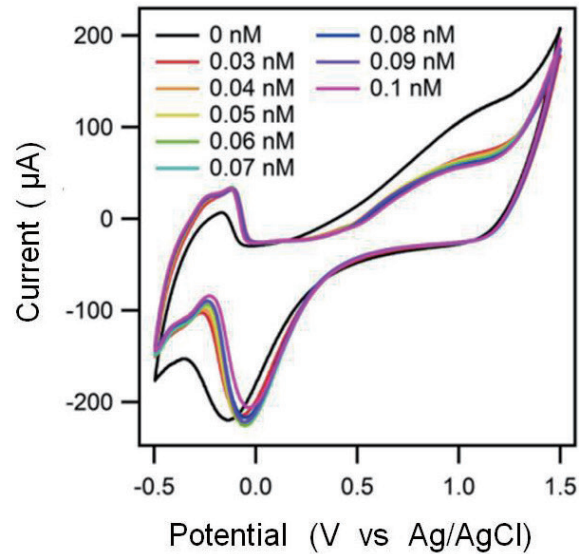

(a)

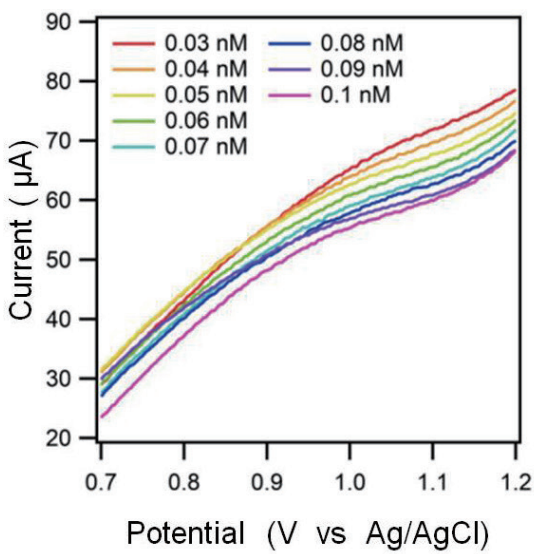

(b)

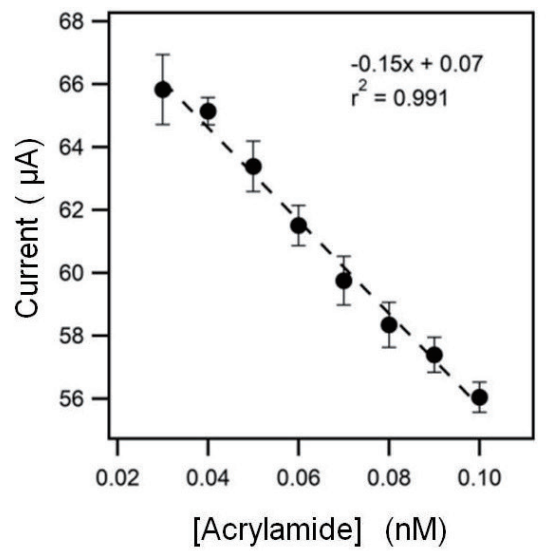

(c)

Fig. 8. (Color online) (a) Cyclic voltammograms of various concentrations of acrylamide Hb-Pt-BDD, (b) its magnification, and (c) peak currents as functions of acrylamide concentration. 


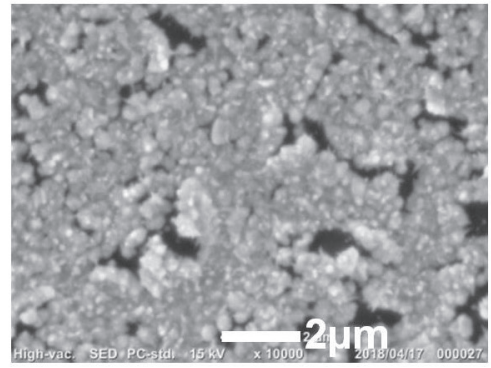

(a)

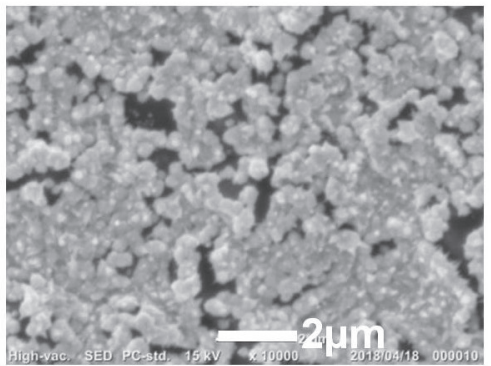

(b)

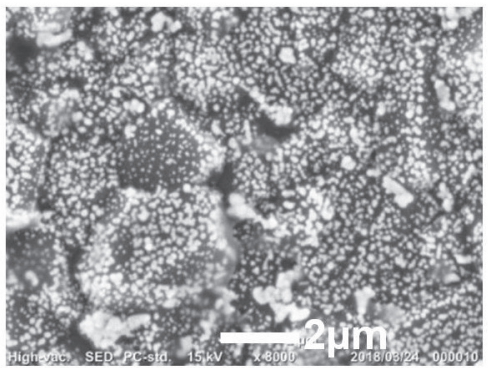

(c)

Fig. 9. SEM images of Hb-Pt-BDD (a) as-prepared, (b) after 10 applications as acrylamide sensors, and (c) after cleaning with $\mathrm{CV}$ in $0.1 \mathrm{M} \mathrm{NaClO}_{4}$.

Table 1

Chemical compositions of Pt-BDD electrode in the absence of $\mathrm{Hb}$ and $\mathrm{Hb}-\mathrm{Pt}-\mathrm{BDD}$ electrodes as prepared, application as acrylamide sensors, and after cleaning with $\mathrm{CV}$ in $0.1 \mathrm{~m} \mathrm{NaClO}_{4}$ solution.

\begin{tabular}{lcccc}
\hline Element & $\begin{array}{c}\text { Before Hb modification } \\
(\% \text { mass })\end{array}$ & $\begin{array}{c}\text { As prepared } \\
\text { (\% mass) }\end{array}$ & $\begin{array}{c}\text { After application } \\
(\% \text { mass })\end{array}$ & $\begin{array}{c}\text { After cleaning } \\
(\% \text { mass })\end{array}$ \\
\hline $\mathrm{C}$ & 4.61 & 16.77 & 10.96 & 8.25 \\
$\mathrm{O}$ & 0.59 & 1.81 & 0.91 & 1.24 \\
$\mathrm{Fe}$ & $\mathrm{NA}$ & 0.15 & 0.09 & $\mathrm{NA}$ \\
$\mathrm{Pt}$ & 94.80 & 81.27 & 87.98 & 90.60 \\
\hline
\end{tabular}

decreased. The decrease in the mass percentage of $\mathrm{Fe}$ into zero indicated that $\mathrm{Hb}$ could be totally released from the Pt-BDD surface. Further comparison with Pt-BDD before modification with $\mathrm{Hb}$ shows that the amount of Pt slightly decreases (by around 4\%), suggesting good stability of Pt particles on the BDD surface.

\section{Conclusions}

Pt particles have been successfully modified on a BDD surface using several steps, including the wet chemical seeding of Pt particles, the electrochemical overgrowth of Pt seeds, thermal annealing at $700{ }^{\circ} \mathrm{C}$ under $\mathrm{N}_{2}$ atmosphere, and refresh and activation steps of Pt-BDD by CV. This method gives the high stability of $\mathrm{Pt}$ particles induced by modification with $\mathrm{Hb}$ and low LoD $(0.0085 \mathrm{nM})$ and LoQ $(0.026 \mathrm{nM})$ for acrylamide sensors. This shows that the method of preparing Pt-BDD was promising for online applications, including food and environmental monitoring.

\section{Acknowledgments}

This research is partly supported by the Hibah Disertasi Doktor 2018 of KEMENRISTEKDIKTI Republic Indonesia with Contract No. 0795/K4/KM/2018. 


\section{References}

1 S. Garabagiu and G. Mihailescu: J. Electroanal. Chem. 659 (2011) 196. https://doi.org/10.1016/ j.jelechem.2011.06.003

2 B. Batra, S. Lata, and C. S. Pundir: Bioprocess. Biosyst. Eng. 36 (2013) 1591. https://doi.org/10.1007/s00449013-0931-5

3 I. Notardonato, P. Avino, A. Centola, G. Cinelli, and M. V. Russo: Anal. Bioanal. Chem. 405 (2013) 6137. https://doi.org/10.1007/s00216-013-7001-3

4 Q. Hu, X. Xu, Y. Fu, and Y. Li: Food Control 56 (2015) 135. https://doi.org/10.1016/j.foodcont.2015.03.021

5 A. Krajewska, J. Radecki, and H. Radecka: Sensors 8 (2008) 5832. https://doi.org/10.3390/s8095832

6 M. Li, G. Zhao, R. Geng, and H. Hu: Bioelectrohem. 74 (2008) 217. https://doi.org/10.1016/ j.bioelechem.2008.08.004

7 K. Umam, E. Saepudin, and T. A. Ivandini: IOP Conf. Ser.: Mater. Sci. Eng. 188 (2016) 1. https://doi. org/10.1088/1757-899X/188/1/012006

8 W. Sun, L. Cao, Y. Deng, S. Gong, F. Shi, G. Li, and Z. Sun: Anal. Chim. Acta 781 (2013) 41. https://doi. org/10.1016/j.aca.2013.04.010

9 J. V. Macpherson: Phys. Chem. Chem. Phys. 17 (2015) 2935. https://doi.org/10.1039/c4cp04022h

10 T. A. Ivandini, R. Sato, Y. Makide, A. Fujishima, and Y. Einaga: Chem. Lett. 33 (2004) 1330. https://doi. org/10.1246/cl.2004.1330

11 F. Pino, T. A. Ivandini, K. Nakata, A. Fujishima, A. Merkoçi, and Y. Einaga: Anal. Sci. 31 (2015) 1061. https:// doi.org/10.2116/analsci.31.1061

12 B. Zargar, N. R. Sahraie, and F. Khoshnam: Anal. Lett. 42 (2009) 1407. https://doi. org/10.1080/00032710902954441

13 A. Stobiecka, H. Radecka, and J. Radecki: Biosens. Bioelectron. 22 (2007) 2165. https://doi.org/10.1016/ j.bios.2006.10.008

14 W. T. Wahyuni, T. A. Ivandini, P. K. Jiwanti, E. Saepudin, J. Gunlazuardi, and Y. Einaga: Electrochemistry 83 (2015) 357. https://doi.org/10.5796/electrochemistry.83.357

15 L. La-Torre-Riveros, E. Abel-Tatis, A. E. Méndez-Torres, D. A. Tryk, M. Prelas, and C. R. Cabrera, J. Nanopart. Res. 13 (2011) 2997. https://doi.org/10.1007/s11051-010-0196-8

16 L. La-Torre-Riveros, R. Guzman-Blas, A. E. Mendez-Torres, M. Prelas, D. A. Tryk, and C. R. Cabrera: ACS Appl. Mater. Interfaces 4 (2012) 1134. https://doi.org/10.1021/am2018628

17 T. A. Ivandini and Y. Einaga: Diamond Electrochemistry, In: Reedijk, J. (Ed.) Elsevier Reference Module in Chemistry, Molecular Sciences and Chemical Engineering (Elsevier, Waltham, MA, 2017). https://doi. org/10.1016/B978-0-12-409547-2.12190-0.

18 T. A. Ivandini and Y. Einaga: Chem. Commun. 53 (2017) 1338. https://doi.org/10.1039/c6cc08681k

19 F. Gao, N. Yang, W. Smirnov, H. Obloh, and C. E. Nebel: Electrochim. Acta 90 (2013) 445. https://doi. org/10.1016/j.electacta.2012.12.050

20 R. Bortolomeazzi, M. Munari, M. Anese, and G. Verardo: Food Chem. 135 (2012) 2687. https://doi.org/10.1016/ j.foodchem.2012.07.057

21 R. Hoffmann, A. Kriele, H.Obloh, J. Hees, and M. Wolfer: Appl. Phys. Lett. 97 (2010) 052103. https://doi. org/10.1063/1.3476346

22 P. Kim, J.B. Joo, W. Kim, J. Kim, I. K. Song, and J. Yi: J. Power Sources 160 (2006) 987. https://doi. org/10.1016/j.jpowsour.2006.02.050

23 F. Gao, N. Yang, and C. E. Nebel: Electrochim. Acta 112 (2013) 493. https://doi.org/10.1016/j.electacta.2013.09.005

24 H. Y. Xu, Y. N. Guo, Y. Wang, J. Zau, J. H. Kang, Q. Gao, H. H. Tan, and C. Jagadish: Appl. Phys. Lett. 106 (2009) 083514. https://doi.org/10.1063/1.3248372

25 K. Yamamoto, D. M. Kolb, R. Kotz, and G. Lehmpfuhl: J. Electroanal. Chem. Interfacial Electrochem. 96 (1979) 233. https://doi.org/10.1016/S0022-0728(79)80380-0

26 Y. Honda, T. A. Ivandini, T. Watanabe, K. Muarata, and Y. Einaga: Diamond Relat. Mater. 40 (2013) 7. https:// doi.org/10.1016/j.diamond.2013.09.001

27 J. C. Hamilton and J. M. Blakely: J. Vac. Sci. Technol. 15 (1978) 559. https://doi.org/10.1116/1.569472

28 M. Friedman: J. Agric. Food Chem. 51 (2003) 4504. https://doi.org/10.1021/jf030204+

29 H. Y. Gu, A. M. Yu, and H. Y. Chen: J. Electroanal. Chem. 516 (2001) 119. https://doi.org/10.1016/S00220728(01)00669-6

30 J. M. Pinggarón, Y. P. Sedeńo, and G. A. Cortẽs: Electrochim. Acta 53 (2008) 5848. https://doi.org/10.1016/ j.electacta.2008.03.005 


\section{About the Authors}

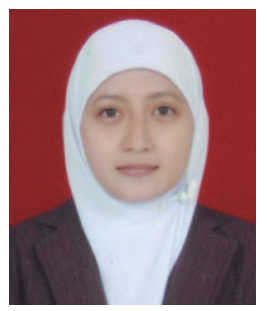

Retno Wulandari received her B.S. degree from the State University of Semarang, Indonesia, in 2007 and M.S. degree from Universitas Gadjah Mada, Indonesia in 2011. She is now a Ph.D. student in the Department of Chemistry at Universitas Indonesia. Her research interests are in electrochemical biosensors and nanomaterials.

(retno.wulandari51@sci.ui.ac.id)

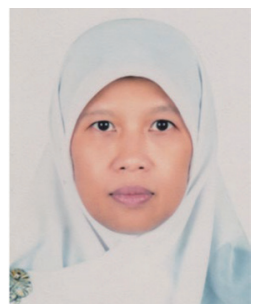

Tribidasari Anggraningrum Ivandini received her B.S. and M.S. degrees from Universitas Indonesia, Jakarta, Indonesia in 1993 and 1997, respectively. In 2003, she received her Ph.D. degree from the University of Tokyo, Japan. From 2003 to 2007, she was an assistant professor at Keio University, Japan. Since 1997, she has been a lecturer at Universitas Indonesia and became an associate professor in 2010. Her research interests are in diamond electrochemistry, sensors, and biosensors. (ivandini.tri@sci.ui.ac.id)

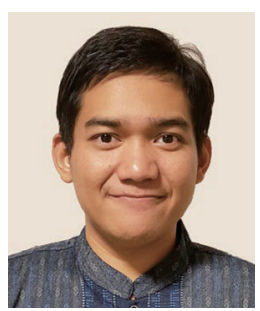

Irkham received his B.S. degree from the University of Indonesia, Indonesia in 2013 and his M.S. degree from Keio University, Japan, in 2016. Since 2017, he has continued his Ph.D. studies in the same university under the supervision of Prof. Yasuaki Einaga. His research interests are in ECL and sensors. (irkham@chem.keio.ac.jp)

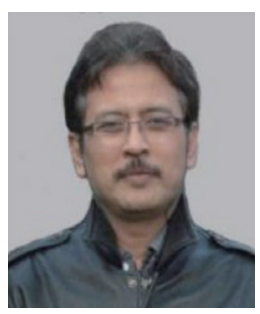

Endang Saepudin received his B.S. degree from Universitas Indonesia, Jakarta, Indonesia in 1985 and his Ph.D. degree from McMaster University, Canada, in 1995. Since 1986, he has been a lecturer at Universitas Indonesia, Indonesia. His research interests are in carbohydrates and biosensors. (ending.saefudin@sci.ui.ac.id)

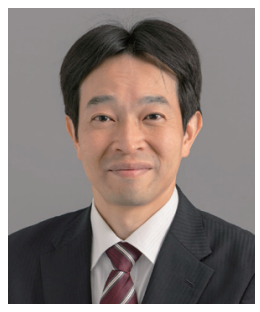

Yasuaki Einaga received his B.S., M.S, and Ph.D. degrees from the University of Tokyo, Japan, in 1994, 1996, and 1999, respectively. He started a faculty career as an assistant professor in Keio University in 2001 and then promoted to professor in 2011. He is also a research director of JST-ACCEL. His research interests include functional materials science and electrochemistry. (einaga@chem.keio.ac.jp) 